Case Report

\title{
Mifepristone Improves Octreotide Efficacy in Resistant Ectopic Cushing's Syndrome
}

\author{
Andreas G. Moraitis ${ }^{1}$ and Richard J. Auchus ${ }^{2}$ \\ ${ }^{1}$ Corcept Therapeutics, 149 Commonwealth Drive, Menlo Park, CA 94025, USA \\ ${ }^{2}$ Division of Metabolism, Diabetes, and Endocrinology, Department of Internal Medicine, University of Michigan, \\ 1150 West Medical Center Drive, Ann Arbor, MI 48109, USA
}

Correspondence should be addressed to Andreas G. Moraitis; andreas.moraitis@yahoo.com

Received 18 November 2015; Accepted 26 January 2016

Academic Editor: Hidetoshi Ikeda

Copyright (C) 2016 A. G. Moraitis and R. J. Auchus. This is an open access article distributed under the Creative Commons Attribution License, which permits unrestricted use, distribution, and reproduction in any medium, provided the original work is properly cited.

\begin{abstract}
A 30-year-old Caucasian man presented with severe Cushing's syndrome (CS) resulting from ectopic adrenocorticotropin syndrome (EAS) from a metastatic pancreatic neuroendocrine tumor. The patient remained hypercortisolemic despite treatment with steroidogenesis inhibitors, chemotherapy, and octreotide long-acting release (LAR) and was enrolled in a 24-week, phase 3 clinical trial of mifepristone for inoperable hypercortisolemia. After mifepristone was added to ongoing octreotide LAR treatment, EAS symptoms essentially resolved. Cortisol decreased dramatically, despite mifepristone's competitive glucocorticoid receptor antagonist effects. The clinical and biochemical effects reversed upon mifepristone discontinuation despite the continued use of octreotide LAR therapy. Substantial improvement in octreotide LAR efficacy with mifepristone use was noted in this patient with ectopic CS, consistent with upregulation of somatostatin receptors previously downregulated by hypercortisolemia.
\end{abstract}

\section{Introduction}

Chronic hypercortisolemia resulting from ectopic adrenocorticotropin hormone secretion (EAS) (nonpituitary) accounts for approximately $10 \%$ of all adrenocorticotropin- (ACTH-) dependent Cushing's syndrome (CS) $[1,2]$. Although localized primarily in the chest, consisting of mainly bronchial (foregut) neuroendocrine tumors (NETs) and small-cell lung carcinoma, EAS is also associated with medullary thyroid carcinomas, gastrointestinal NETs, and thymic NETs, and, less frequently, other tumor types [2-4]. The primary treatment of EAS is surgical removal of the tumor when possible. If surgical resection is not possible or successful, medical therapy is necessary.

Depending on the etiology, EAS-associated tumors can express multiple somatostatin receptor subtypes (e.g., SST2, SST1, and SST5) [5]. This finding has enabled the use of somatostatin receptor scintigraphy (e.g., $\left[{ }^{111} \mathrm{In}\right]$-pentetreo-tide or octreoscan and $\left[{ }^{68} \mathrm{Ga}\right]$-octreotide-derivative positron emission tomography) for tumor localization and, in some cases, targeted treatment with somatostatin analog, octreotide $[2,4$, 6-9], which has high affinity for SST2 [10]. However, octreotide therapy is frequently ineffective, limiting its utility as a therapeutic and diagnostic agent $[11,12]$.

Glucocorticoids have been shown to directly downregulate SST2 expression in human NET cells [13], as well as in human and murine corticotrope adenoma cells $[14,15]$. The downregulation of SST2 in human neuroendocrine cell lines was found to be reversed with the addition of mifepristone, a glucocorticoid receptor (GR) antagonist [13]. Mifepristone may also directly influence tumoral SST2 expression levels in human NETs [16]. Medical therapy with mifepristone in 2 patients with EAS resulted in increased posttreatment uptake, positive octreoscan, and subsequent tumor localization [16]. In contrast, the capacity of mifepristone to enhance the clinical therapeutic efficacy of somatostatin analogs in reducing ACTH and cortisol production has not yet been demonstrated. We report a case of EAS demonstrating a synergistic effect of mifepristone in combination with octreotide longacting release (LAR). 
TABLE 1: Biochemistry evaluations during treatment with mifepristone* .

\begin{tabular}{lcccccc}
\hline Test (normal range) & Baseline (before MIFE) & Week 6 & Week 10 & Week 16 & Week 24 & 2-week follow-up (off MIFE) \\
\hline $\begin{array}{l}\text { ACTH, pg/mL } \\
(7-50 \mathrm{pg} / \mathrm{mL})\end{array}$ & 345 & 279 & 188 & 250 & 304 & 652 \\
\hline $\begin{array}{l}\mathrm{UFC}, \mathrm{mcg} / 24 \mathrm{~h} \\
(2.0-42.4 \mathrm{mcg} / 24 \mathrm{~h})\end{array}$ & 2250 & 1536 & 104 & 122 & 434 & 4716 \\
\hline $\begin{array}{l}\text { Serum cortisol, } \mathrm{mcg} / \mathrm{dL} \\
(8 \mathrm{AM}, 4.0-22.0 \mathrm{mcg} / \mathrm{dL})\end{array}$ & 46 & 41 & 31 & 31 & 37 & 68 \\
\hline $\begin{array}{l}\text { Late-night salivary cortisol, } \mathrm{mcg} / \mathrm{dL} \\
(10 \mathrm{PM}-11 \mathrm{PM}, \leq 0.09 \mathrm{mcg} / \mathrm{dL})\end{array}$ & 1.71 & 2.18 & 0.56 & 0.73 & 1.49 & 4.91 \\
\hline
\end{tabular}

* Patient continued to receive octreotide LAR $30 \mathrm{mg}$ every month throughout the study. ACTH denotes adrenocorticotropin hormone, LAR long-acting release, MIFE mifepristone, and UFC urinary-free cortisol. To convert the values for UFC to nanomoles per $24 \mathrm{~h}$, multiply by 2.76 . To convert the values for ACTH to picomoles per liter, multiply by 0.22 . To convert the values for serum cortisol and late-night salivary cortisol to nanomoles per liter, multiply by 27.6 .

Octreotide LAR $30 \mathrm{mg}$ every month

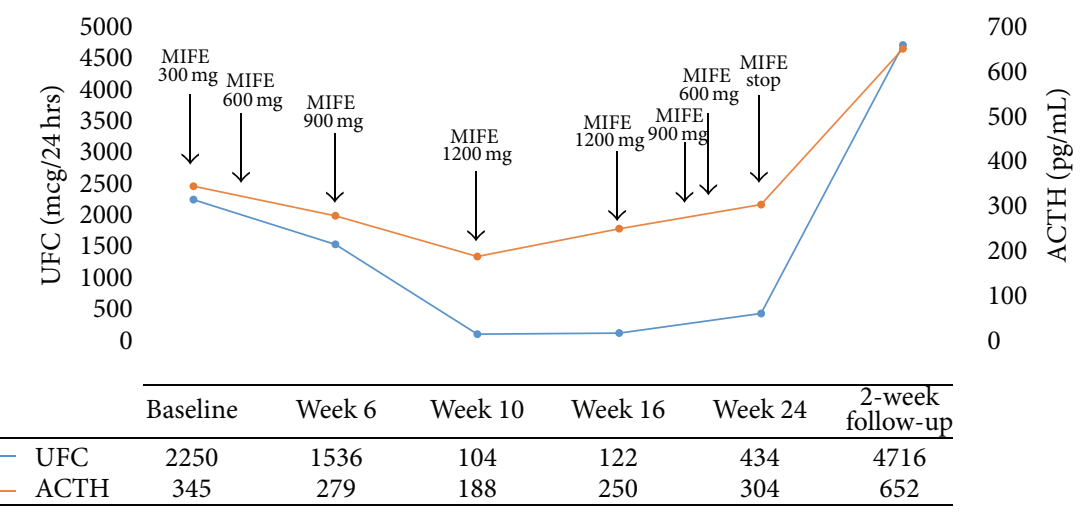

FIGURE 1: UFC and ACTH concentrations during treatment with mifepristone and octreotide LAR. ACTH denotes adrenocorticotropin hormone, LAR long-acting release, MIFE mifepristone, and UFC urinary-free cortisol. To convert the values for UFC to nanomoles per $24 \mathrm{~h}$, multiply by 2.76. To convert the values for ACTH to picomoles per liter, multiply by 0.22 .

\section{Case}

A 30-year-old man presented with weight gain, hypertension, diabetes, proximal muscle weakness, and nephrolithiasis. He developed moon facies, abdominal striae, and disproportionate supraclavicular and dorsocervical fat pads. Endocrine testing and imaging studies revealed a pancreatic NET with involvement of the inferior vena cava and other local structures. After resection of the tumor, the postoperative ACTH was not suppressed; however, cushingoid features improved significantly. Approximately 2 years later, symptoms of EAS recurred. Ketoconazole and chemotherapy were started but were not successful in resolving hypercortisolemia. Three months later, octreotide LAR was initiated, and the dose was gradually increased to $30 \mathrm{mg}$ every month. A partial biochemical response was noted (ACTH decreased from $517 \mathrm{pg} / \mathrm{mL}(113.7 \mathrm{pmol} / \mathrm{L})$ to $345 \mathrm{pg} / \mathrm{mL}$ $(75.9 \mathrm{pmol} / \mathrm{L}))$, but the patient's symptoms of EAS were not controlled. After 3 months of therapy with octreotide LAR, the patient was enrolled in a 24 -week, phase 3 clinical trial of mifepristone for inoperable hypercortisolemia (clinicaltrials.gov identifier: NCT00569582 [17]). Prior to the start of mifepristone, baseline urinary-free cortisol (UFC) was $2250 \mathrm{mcg} / 24$ hours $(6207 \mathrm{nmol} / 24$ hours) and ACTH was $345 \mathrm{pg} / \mathrm{mL}(75.9 \mathrm{pmol} / \mathrm{L})$. Late-night salivary cortisol $(1.71 \mathrm{mcg} / \mathrm{dL}(47.2 \mathrm{nmol} / \mathrm{L}))$ and serum cortisol $(46 \mathrm{mcg} / \mathrm{dL}$ $(1256 \mathrm{nmol} / \mathrm{L}))$ were also elevated (Table 1$)$. At the time of enrollment, the patient had overtly cushingoid features, including moon facies, plethora, and enlarged dorsocervical and supraclavicular fat pads; purple striae; bruising; edema; and proximal muscle weakness that was so severe that he was unable to rise from a chair without use of his hands. He also had ongoing diabetes, depression, and hypertension associated with hypokalemia. Mifepristone was initiated at a daily dose of $300 \mathrm{mg}$ and gradually increased to $1200 \mathrm{mg}$ per protocol. The patient continued to receive octreotide LAR throughout the duration of the trial. By week 4, insulin therapy was discontinued and by week 12 , his cushingoid features essentially resolved. In addition to clinical improvement, a dramatic decrease in cortisol and ACTH was noted during therapy with mifepristone and octreotide LAR (Figure 1, Table 1). At week 20, mifepristone was briefly stopped for significant fatigue, low appetite, and nausea. Mifepristone was then resumed at a daily dose of $900 \mathrm{mg}$ and 1 week later reduced to $600 \mathrm{mg}$; no changes were made to octreotide LAR dose. At week 24, his UFC and ACTH levels were 
$434 \mathrm{mcg} / 24$ hours (1198.7 nmol/24 hours) and $304 \mathrm{pg} / \mathrm{mL}$ (66.9 pmol/L), respectively, and mifepristone was stopped per study protocol. During withdrawal of mifepristone, the cortisol and ACTH rose, and 12 days after mifepristone was stopped, clinical signs and symptoms of EAS returned. After 2 weeks, his UFC and ACTH increased to $4716 \mathrm{mcg} / 24$ hours (13016 nmol/24 hours) and $652 \mathrm{pg} / \mathrm{mL}$ (143.4 pmol/L), respectively (Figure 1, Table 1). Mifepristone was resumed for an additional 12-month extension period. Octreotide LAR was discontinued after 2 months and the patient continued with mifepristone for control of his CS-related symptoms. The collection of cortisol and ACTH data was less frequent during the extension study. At the time octreotide was discontinued, the patient's ACTH and serum cortisol were $652 \mathrm{pg} / \mathrm{mL}$ $(143.4 \mathrm{pmol} / \mathrm{L})$ and $67.8 \mathrm{mcg} / \mathrm{dL}(1871 \mathrm{nmol} / \mathrm{L})$, respectively. After 12 months in the extension phase, substantial increases in $\mathrm{ACTH}(3738 \mathrm{pg} / \mathrm{mL}(822.4 \mathrm{pmol} / \mathrm{L}))$, serum cortisol $(135.2 \mathrm{mcg} / \mathrm{dL}(3732 \mathrm{nmol} / \mathrm{L}))$, and UFC $(10716.5 \mathrm{mcg} / 24$ hours (29577.5 nmol/24 hours)) were observed.

\section{Discussion}

This case describes a patient with pancreatic NET associated with EAS, in whom treatment with the somatostatin analog octreotide became much more effective in controlling cortisol and ACTH after the addition of GR antagonist therapy with mifepristone. Several studies have demonstrated a relationship between GR sensitivity and response to somatostatin analogs $[13,15,18]$. Corticotrope adenomas contain multiple somatostatin receptors, primarily SST5 and lower levels of SST2 [19]. Using murine corticotrope tumor cells, van der Hoek et al. demonstrated a dexamethasone-dependent inhibitory effect of octreotide treatment targeting SST2 that was not found with analogs that targeted primarily SST5 [15]. This result suggests that analogs targeting SST2 are particularly susceptible to glucocorticoid-mediated downregulation, which also might explain the lower SST2 expression found in human corticotrope adenomas and the frequent lack of response to octreotide in patients with Cushing's disease (CD) [14].

Ferrau et al. studied whether a brief treatment with mifepristone modulates the response to acute octreotide administration in 5 patients with CD [18]. This study showed that brief mifepristone pretreatment does not modify ACTH and cortisol response to acute octreotide administration in patients with CD. However, the authors noted that, regardless of mifepristone treatment, decreases in ACTH and cortisol after acute injection of octreotide were observed in patients with lower cortisol levels following dexamethasone suppression testing. Together these results suggest that an intact glucocorticoid signaling pathway within these cells is required for downregulation of SST2.

This model could explain some of the variability in response to SST2 analogs among the various tumor types associated with EAS. In vitro studies in small-cell lung cancer cell lines demonstrated defects in GR function that could lead to glucocorticoid resistance $[20,21]$. de Bruin et al. have shown a dexamethasone dose-dependent downregulation of SST2 expression in the human pancreatic NET cell line BON and the medullary thyroid carcinoma cell line TT, which disappeared after treating these cells with mifepristone [13]. However, the authors reported no glucocorticoid-mediated effects in DMS cells from a small-cell lung cancer line with severe glucocorticoid resistance.

At least $20 \%$ to $30 \%$ of patients with EAS will suppress plasma and urinary steroids to less than $50 \%$ of baseline values during high-dose dexamethasone suppression testing [22]. These patients are clinically and hormonally difficult to differentiate from patients with $\mathrm{CD}$, particularly if the tumor is not localized. With the development of targeting radionuclide diagnostics and therapeutics using somatostatin analogs (theranostics), an additional role of mifepristone might be as a "radiosensitizing" agent. Ejaz et al. reported 2 patients with EAS and occult tumor sources despite multiple imaging attempts whose bronchial NETs were localized via octreotide scintigraphy only after receiving treatment with mifepristone for several weeks [2]. Of note, only 1 of the 2 patients was found to be responsive to high-dose dexamethasone testing. Therefore, additional data are required to determine whether a positive response to $1 \mathrm{mg}$ of dexamethasone in patients with $\mathrm{CD}$ or $8 \mathrm{mg}$ in patients with EAS can predict the response to somatostatin analogs targeting the SST2.

In this case, the addition of mifepristone to ongoing octreotide LAR led to a substantial reduction in ACTH and cortisol in our patient with previously resistant EAS associated with severe hypercortisolemia. This effect was lost upon discontinuation of mifepristone after 24 weeks of treatment. Of note, the reduction in ACTH during mifepristone cotreatment was not as pronounced as the observed reduction in cortisol. An assessment of ACTH precursors (proopiomelanocortin and pro-ACTH), which can be markedly elevated in patients with EAS $[23,24]$, would have provided additional insight. However, measuring precursors and biologically active ACTH would have required separation via chromatography, which was not performed, nor did we have access to patient tumor tissue to assess SST receptor expression. Nonetheless, to our knowledge, this is the first clinical case report that demonstrates a relationship between GR antagonism with mifepristone and increased therapeutic efficacy of the somatostatin analog octreotide, consistent with upregulation of somatostatin receptors previously downregulated by hypercortisolemia.

\section{Disclosure}

This paper was prepared according to the International Society for Medical Publication Professionals' "Good Publication Practice for Communicating Company-Sponsored Medical Research: The GPP3 Guidelines" and the International Committee of Medical Journal Editors' "Uniform Requirements for Manuscripts Submitted to Biomedical Journals.”

\section{Conflict of Interests}

Dr. Moraitis is an Associate Medical Director at Corcept Therapeutics and Dr. Auchus is a consultant for Corcept Therapeutics. 


\section{Authors' Contribution}

Drs. Moraitis and Auchus conceptualized the case report and drafted and/or critically reviewed the paper. The authors read and approved the final paper.

\section{Acknowledgments}

The authors wish to thank Sarah Mizne, PharmD of MedVal Scientific Information Services, LLC, and Dat Nguyen, PharmD of Corcept Therapeutics, for providing professional writing and editorial assistance. Some of the data for this patient case report came from a clinical trial that was sponsored by Corcept Therapeutics, Menlo Park, CA. Funding to support the preparation of this paper was provided to MedVal Scientific Information Services, LLC, by Corcept Therapeutics.

\section{References}

[1] B. L. Wajchenberg, B. B. Mendonca, B. Liberman et al., "Ectopic adrenocorticotropic hormone syndrome," Endocrine Reviews, vol. 15, no. 6, pp. 752-787, 1994.

[2] S. Ejaz, R. Vassilopoulou-Sellin, N. L. Busaidy et al., "Cushing syndrome secondary to ectopic adrenocorticotropic hormone secretion: the University of Texas MD Anderson Cancer Center experience," Cancer, vol. 117, no. 19, pp. 4381-4389, 2011.

[3] I. Ilias, D. J. Torpy, K. Pacak, N. Mullen, R. A. Wesley, and L. K. Nieman, "Cushing's syndrome due to ectopic corticotropin secretion: twenty years' experience at the National Institutes of Health," Journal of Clinical Endocrinology and Metabolism, vol. 90, no. 8, pp. 4955-4962, 2005.

[4] A. M. Isidori, G. A. Kaltsas, C. Pozza et al., "The ectopic adrenocorticotropin syndrome: clinical features, diagnosis, management, and long-term follow-up," Journal of Clinical Endocrinology and Metabolism, vol. 91, no. 2, pp. 371-377, 2006.

[5] J. C. Reubi and B. Waser, "Concomitant expression of several peptide receptors in neuroendocrine tumours: molecular basis for in vivo multireceptor tumour targeting," European Journal of Nuclear Medicine and Molecular Imaging, vol. 30, no. 5, pp. 781-793, 2003.

[6] K. von Werder, O. A. Muller, and G. K. Stalla, "Somatostatin analogs in ectopic corticotropin production," Metabolism, vol. 45, no. 8, supplement 1, pp. 129-131, 1996.

[7] M. Phlipponneau, M. Nocaudie, J. Epelbaum et al., "Somatostatin analogs for the localization and preoperative treatment of an adrenocorticotropin-secreting bronchial carcinoid tumor," Journal of Clinical Endocrinology and Metabolism, vol. 78, no. 1, pp. 20-24, 1994.

[8] S. W. Lamberts, W. W. de Herder, E. P. Krenning, and J. C. Reubi, "A role of (labeled) somatostatin analogs in the differential diagnosis and treatment of Cushing's syndrome," Journal of Clinical Endocrinology and Metabolism, vol. 78, no. 1, pp. 17-19, 1994.

[9] Z. G. Özkan, S. Kuyumcu, D. Balköse, B. Özkan, and N. Aksakal, "The value of somatostatin receptor imaging with In111 Octreotide and/or Ga-68 DOTATATE in localizing Ectopic ACTH producing tumors," Malecular Imaging and Radionuclide Therapy, vol. 22, no. 2, pp. 49-55, 2013.
[10] S. Grozinsky-Glasberg, I. Shimon, M. Korbonits, and A. B. Grossman, "Somatostatin analogues in the control of neuroendocrine tumours: efficacy and mechanisms," Endocrine-Related Cancer, vol. 15, no. 3, pp. 701-720, 2008.

[11] N. W. Cheung and S. C. Boyages, "Failure of somatostatin analogue to control Cushing's syndrome in two cases of ACTHproducing carcinoid tumours," Clinical Endocrinology, vol. 36, no. 4, pp. 361-367, 1992.

[12] G. I. Uwaifo, C. A. Koch, B. Hirshberg et al., "Is there a therapeutic role for octreotide in patients with ectopic cushing's syndrome?" Journal of Endocrinological Investigation, vol. 26, no. 8, pp. 710-717, 2003.

[13] C. de Bruin, R. A. Feelders, A. M. Waaijers et al., "Differential regulation of human dopamine D2 and somatostatin receptor subtype expression by glucocorticoids in vitro," Journal of Molecular Endocrinology, vol. 42, no. 1, pp. 47-56, 2009.

[14] G. K. Stalla, S. J. Brockmeier, U. Renner et al., "Octreotide exerts different effects in vivo and in vitro in Cushing's disease," European Journal of Endocrinology, vol. 130, no. 2, pp. 125-131, 1994.

[15] J. van der Hoek, M. Waaijers, P. M. van Koetsveld et al., "Distinct functional properties of native somatostatin receptor subtype 5 compared with subtype 2 in the regulation of ACTH release by corticotroph tumor cells," American Journal of PhysiologyEndocrinology and Metabolism, vol. 289, no. 2, pp. E278-E287, 2005.

[16] C. de Bruin, L. J. Hofland, L. K. Nieman et al., "Mifepristone effects on tumor somatostatin receptor expression in two patients with Cushing's syndrome due to ectopic adrenocorticotropin secretion," Journal of Clinical Endocrinology and Metabolism, vol. 97, no. 2, pp. 455-462, 2012.

[17] M. Fleseriu, B. M. K. Biller, J. W. Findling, M. E. Molitch, D. E. Schteingart, and C. Gross, "Mifepristone, a glucocorticoid receptor antagonist, produces clinical and metabolic benefits in patients with Cushing's syndrome," Journal of Clinical Endocrinology and Metabolism, vol. 97, no. 6, pp. 2039-2049, 2012.

[18] F. Ferrau, F. Trimarchi, and S. Cannavo, "Adrenocorticotropin responsiveness to acute octreotide administration is not affected by mifepristone premedication in patients with Cushing's disease," Endocrine, vol. 47, no. 2, pp. 550-556, 2014.

[19] C. de Bruin, A. M. Pereira, R. A. Feelders et al., "Coexpression of dopamine and somatostatin receptor subtypes in corticotroph adenomas," Journal of Clinical Endocrinology and Metabolism, vol. 94, no. 4, pp. 1118-1124, 2009.

[20] D. W. Ray, A. C. Littlewood, A. J. L. Clark, J. R. E. Davis, and A. White, "Human small cell lung cancer cell lines expressing the proopiomelanocortin gene have aberrant glucocorticoid receptor function," The Journal of Clinical Investigation, vol. 93, no. 4, pp. 1625-1630, 1994.

[21] D. Gaitan, C. R. DeBold, M. K. Turney, P. Zhou, D. N. Orth, and W. J. Kovacs, "Glucocorticoid receptor structure and function in an adrenocorticotropin-secreting small cell lung cancer," Molecular Endocrinology, vol. 9, no. 9, pp. 1193-1201, 1995.

[22] J. W. Findling and J. L. Doppman, "Biochemical and radiologic diagnosis of Cushing's syndrome," Endocrinology and Metabolism Clinics of North America, vol. 23, no. 3, pp. 511-537, 1994. 
[23] A. White and S. Gibson, "ACTH precursors: biological significance and clinical relevance," Clinical Endocrinology, vol. 48, no. 3, pp. 251-255, 1998.

[24] R. L. Oliver, J. R. E. Davis, and A. White, "Characterisation of ACTH related peptides in ectopic Cushing's syndrome," Pituitary, vol. 6, no. 3, pp. 119-126, 2003. 


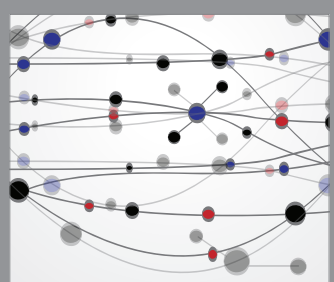

The Scientific World Journal
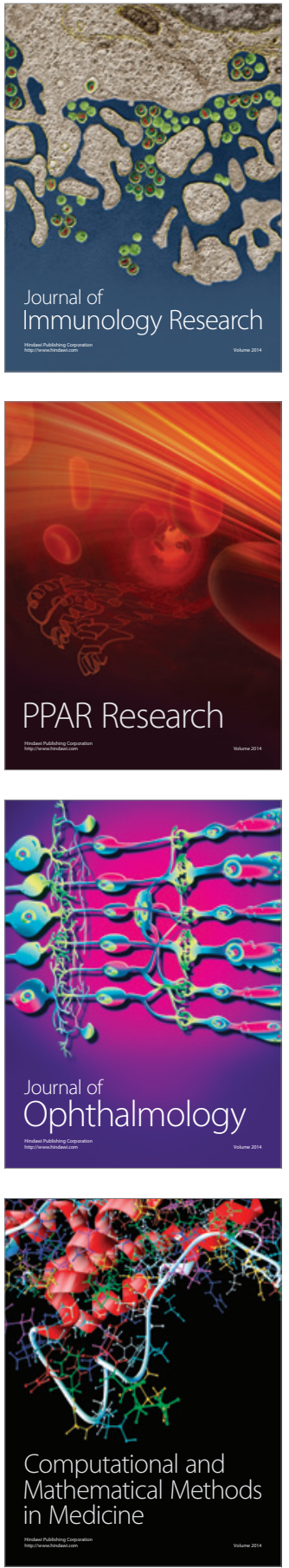

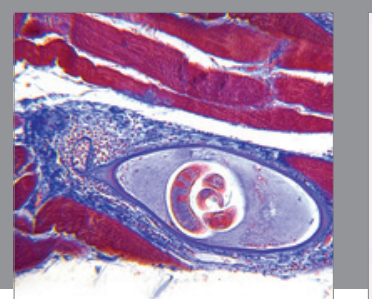

Gastroenterology Research and Practice

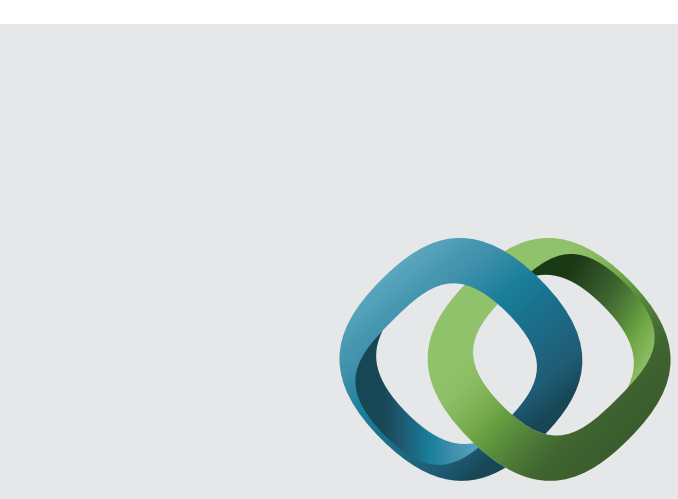

\section{Hindawi}

Submit your manuscripts at

http://www.hindawi.com
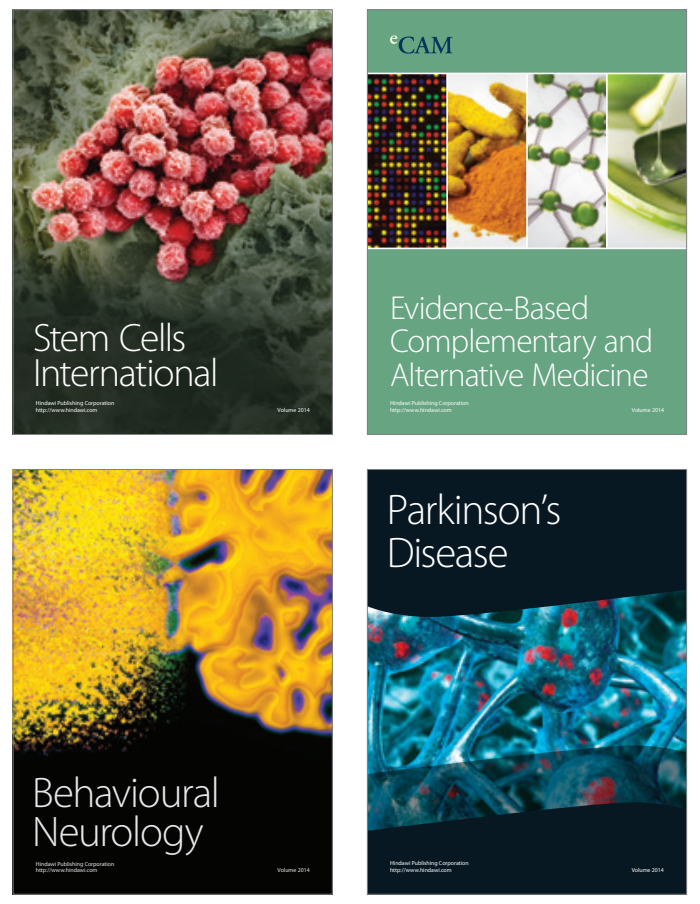
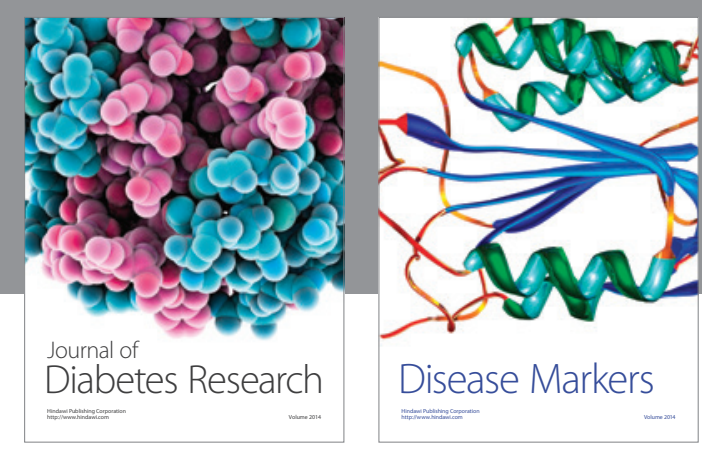

Disease Markers
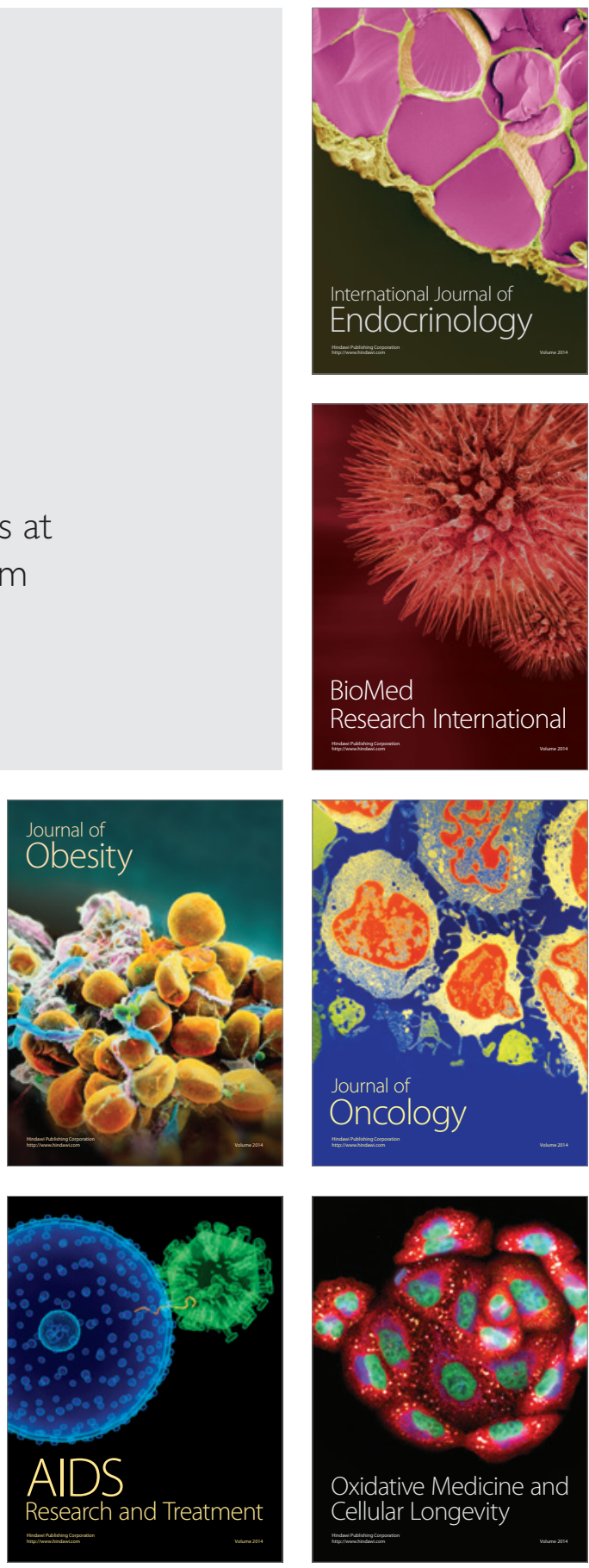